\title{
Formal versus Functional Explanation for a Universal Theory of Syllable Structure: The Case of Vowel Epenthesis in Winnebago*
}

\author{
Stuart Davis \& Karen Baertsch \\ Indiana University \& Southern Illinois University
}

\begin{abstract}
This paper first contrasts formal versus functional explanations for language processes. It suggests that the different types of explanation can be brought together to offer deeper understanding of language processes. It illustrates this by giving a detailed

\footnotetext{
* This paper develops and expands on a talk presented at the meeting of the Linguistic Society in Albuquerque, New Mexico and at the 14th Manchester Phonology Meeting, both held in 2006. We would like to thank Bill Anderson for elucidation of Winnebago (Hocank).
}

Stuart Davis

Department of Linguistics, Indiana University

1021 E. 3rd Street, Bloomington, IN 47405, USA

Phone: 1-812-855-6456; Email: davis@indiana.edu

Karen Baertsch

Department of Linguistics, Faner Hall 3234, 1000 Faner Dr.

Southern Illinois University, Carbondale, IL 62901, USA

Phone: 1-618-536-3385; Email: kbaertsc@siu.edu

Received August 2, 2012; Revised September 4, 2012; Accepted September 10, 2012. 
8 Formal versus Functional Explanation for a Universal Theory of

account of vowel epenthesis in the Native American language Winnebago that references a universal theory of syllable structure.

Keywords: Dorsey's Law, formal explanation, functional explanation, split margin, sonority, syllable structure, Winnebago

\section{Introduction}

One of the major divisions among linguists, and phonologists in particular, concerns the divide between a focus on formal versus functional explanation for common language processes. A formal explanation of a language process is one that references only the language system (usually narrowly defined). In phonology, this means that the explanation for why a process occurs in a particular language may be because that is how the constraints are ranked, or, in a rule-based approach, that is how the rules are ordered. A functional explanation for the occurrence of a process references something outside of the language system. This could include allusion to general cognitive abilities such as perception or to frequency among other factors. The larger issue that underlies the debate over formal versus functional explanation is whether one views the language system as being independent of other cognitive mechanisms or intertwined with more general cognitive mechanism. That is, is the language faculty truly separate of other cognitive faculties, developing independently of them as expressed in works such as Chomsky $(1975,1988)$ and Newmeyer $(2003)$, or, is it as Bybee (2001: 7) claims, "[P]rinciples that govern language are not specific to language, but are in general the same as those that govern other aspects of human cognitive and social behavior"?

While there is a general divide in the field between those advocating a more formal versus a more functional view of language, in phonology the division is often very clear. This division is interestingly independent of whether one favors a 
constraint-based approach to phonology or a rule-based approach. For example, within the constraint-based approach of Optimality Theory there are both formal and functional approaches. Likewise, those who argue against Optimality Theory do so from both a formalist perspective and a functionalist one. As a simple example of contrasting explanations, consider final vowel insertion in the Austronesian language Kambera discussed by Blevins (2004: 156). In this language, a vowel is inserted after a word final consonant. A formal explanation for why this happens would either be that the language has a rule that inserts a vowel after a word final consonant, or, in a constraint-based approach like Optimality Theory, the constraint militating against word final consonants ( Final-C) outranks the constraint against vowel insertion or epenthesis (Dep). This constitutes a formal explanation since only the language system itself is being referred to. On the other hand, after Blevins (2004), we could say the reason that final vowel insertion occurs in Kambera is because the hyperarticulation of a word-final consonant allows its release to be misperceived as a vowel. This is a functional explanation since the reference to perception is outside a narrowly defined language system. Both the formal and functional explanations of Kambera vowel insertion can be criticized at a basic level. The formal explanation does not tell us why in Kambera the ranking of *Final-C over Dep holds and the functional explanation does not tell us why in Kambera the release of a final consonant is more susceptible to be perceived as a vowel as opposed to other languages where released final consonants are not so interpreted (as in Arabic or Berber).

The goal of this paper is to bring together formal and functional explanations by considering a common process of vowel epenthesis found in the Native American language Winnebago (also known as Hocank, Siouan) where a vowel is inserted into a consonant cluster that consists of an obstruent consonant followed by a sonorant consonant. Specifically, in an underlying sequence of obstruent-sonorant-vowel, the potential obstruent-sonorant 
10 Formal versus Functional Explanation for a Universal Theory of

sequence is broken up by the insertion of a vowel in the surface form; the inserted vowel is identical to the post-sonorant vowel. For example, an underlying sequence like /pra/ would be phonetically realized as [para]. This process has become known as Dorsey's Law, named after James Dorsey who first noted the phenomena in his comparative phonology of Siouan languages (Dorsey 1885, see Campbell 1986: 386-387 for details about Dorsey). While the term Dorsey's Law is typically narrowly applied to the Siouan languages, contemporary phonologists sometimes use the term informally for the insertion of a vowel in an obstruent-sonorant sequence regardless of the language in which it might occur. However, in this paper we focus only on its occurrence in Winnebago. The explanation for what motivates Dorsey's Law has engendered some discussion, perhaps, because, as Alderete (1995) has observed, it is somewhat odd for the typologically preferred potential onset cluster (obstruent + sonorant) to be split up by epenthesis in Winnebago while in the same language obstruent-obstruent clusters are not. In the literature, both formal and functional explanations have been offered for this. The main goal of this paper is to show by examining Winnebago that formal and functional explanations are not always incompatible, but that both are needed to achieve deeper understanding for why language processes occur. Before turning to the Winnebago data and analysis in section 4, we first further discuss formal versus functional explanations in phonology in section 2. In section 3, we discuss a formal, sonority based model of the syllable, the split margin syllable, originally developed in Baertsch (2002), since it will play a critical role in our analysis in developing an explanation for Dorsey's Law vowel epenthesis in Winnebago. In Baertsch's model, a coda consonant and a second member of an onset cluster are marked in the same way, such that sonority restrictions on the coda entail effects on possible onset clusters. In our analysis in section 4, we show that this is the key in offering a deeper explanation for why obstruent- 
plus-sonorant clusters normally fail to surface in Winnebago. Nonetheless, functional factors become important for why epenthesis actually occurs. Section 5 concludes suggesting that formal and functional accounts can often work together for deeper understanding of language processes.

\section{Formal versus Functional Explanation in Phonology}

At the beginning of this paper we defined a formal explanation as one in which only the language system itself is referred to. A functional explanation, on the other hand, references phenomena outside of the language system (narrowly defined) for its explanation. Good formal and functional explanations for the same language phenomena often compete and it is typically difficult to decide objectively which explanation is better. As a detailed example of competing formal versus functional explanations for the same phenomenon we consider the debate in the phonological literature regarding the Iambic-Trochaic Law, as discussed by Hayes (1985) and Kager (1993) (see Hyde 2011 for recent discussion). In phonology, the term 'iambic' refers to a system of word stress in which the second of two syllables receives stress (the first being unstressed), whereas the term 'trochaic' pertains to a system in which the first of two syllables receives stress. The relevant observation regarding the Iambic-Trochaic Law (somewhat simplifying) is the following: In iambic stress systems the two syllables that comprise the foot unit (unstressed syllable followed by stress syllable) tend to be durationally uneven (i.e., the stress syllable is significantly longer) whereas in a trochaic stress system the two syllables in a foot unit are durationally more even. Consequently, in iambic stress systems we commonly find that the vowel of the stress syllable lengthens (iambic lengthening) 
12 Formal versus Functional Explanation for a Universal Theory of

or the consonant after it geminates creating a foot in which the first syllable is both light and unstressed while the second is heavy and stressed. In trochaic systems such lengthening of the stress syllable is unattested or at least very unusual. Hayes (1985) and Kager (1993) offer two competing explanations for the observed phenomena in systems of word stress. Hayes offers a functional explanation. He relates iambic lengthening to general perceptual strategies discussed in the psychology literature: when subjects were presented with rhythmically alternating stimuli in which prominence was marked either by intensity or duration, iambic perception resulted when stimuli were marked by duration, but trochaic perception resulted when stimuli were marked by intensity. Consequently, the naturalness of rules of iambic lengthening can be understood in terms of general perceptual strategies; trochaic lengthening would not be expected to occur. On the other hand, Kager (1993) maintains that there is no need for a functional explanation when there is a clear formal account and iambic lengthening has a good formal explanation. Assume a parse of two light syllables into moraic units as shown in $(1 \mathrm{a} \& \mathrm{c})$, where the subscript-w indicates a stressless element and subscript-s a stress element. In an iambic system, with the parse of two light syllables as shown in (1a), the lengthening of the second syllable would result in the moraic parse, $\mu_{\mathrm{w}} \mu_{\mathrm{s}} \mu_{\mathrm{w}}$ in (1b) with alternating weak-strong moras.

(1) Iambic and Trochaic Parses

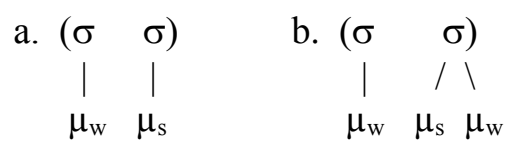




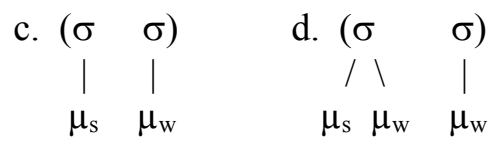

On the other hand in a trochaic system with the parse $\mu_{\mathrm{s}} \mu_{\mathrm{w}}$, (1c), trochaic lengthening would result in the moraic parse $\mu_{\mathrm{s}} \mu_{\mathrm{w}}$ $\mu_{\mathrm{w}}$ in (1d), where there would be a violation of a constraint (lapse) that militates against the occurrence of two adjacent weak elements. Consequently, iambic lengthening can readily occur (1b) since it does not result in a lapse violation; on the other hand, trochaic lengthening would be rarer since it entails a lapse violation. Kager's account constitutes a deeply formal explanation since it references only the language system while Hayes's account is very functional since it alludes to general perceptual strategies. From an objective viewpoint, it is impossible to assess which is a better explanation without taking into account the larger issues mentioned earlier, namely, whether one views the language system as being independent of other cognitive mechanisms or intertwined with more general cognitive mechanism.

The example of iambic lengthening discussed above and the Kambera final vowel insertion mentioned in section 1 constitute cases where formal and functional explanations appear to be competing: there is a clear formal explanation and there is a clear functional one, but which is preferred seems dependent on the bias of the researcher. We will try to reconcile the two types of explanation. In the next section we turn our attention to a different phonological issue: namely, the notion of sonority as a source of explanation for phonological phenomena. We view sonority as a formal construct, but with functional underpinnings. In section 4, we will use this conception to offer a deeper understanding of Dorsey's Law vowel epenthesis in Winnebago. 


\section{A Formal Model of Sonority: The Split Margin Approach to the Syllable}

Reference to sonority to explain phonological patterning within and across syllables has a long history. Much of this is discussed in the seminal work of Parker (2002) who posits a universal sonority hierarchy that is grounded both acoustically in terms of intensity and aerodynamically in terms of intraoral air pressure. Within generative phonology, works like that of Steriade (1982) and Clements (1990) stand out as important contributions toward a formalization of the sonority hierarchy with respect to sonority-based phonotactics within syllables. Certain margin (i.e., consonantal) positions within the syllable, such as the syllable-initial onset and the syllable-final coda, prefer consonants of either lower or higher sonority. However, before the work of Baertsch (2002), syllable based models did not incorporate sonority preferences of various margin positions. A major observation of syllable-based phonotactics is that in languages that allow for onset clusters, the most common type of cluster is one where the first member of an onset is an obstruent and the second is a sonorant (usually a liquid or glide). Further, as noted by Clements (1990) and discussed in such works as Zec (1995) and Davis (2011), there is a typological preference for coda consonants to be of high sonority. As an example, in Italian, single coda consonants can either be a sonorant or a sibilant. Similarly in Tiv (Pulleyblank 1988), a coda consonant can either be a sonorant or voiced fricative. Such consonants are those on the higher end of the sonority scale. Work in phonology from a functional perspective such as Steriade (1999) and Wright (2004) provide us with an understanding as to why the second member of an onset and a coda favor a consonant of high sonority. Both positions do so but for different reasons. As argued for by Steriade (1999) the release of an obstruent is most perceptually salient if the following 
sound is a sonorant. A following obstruent would tend to mask the perceptual salience of the first obstruent, whereas the obstruent's cues are robust if released into a following sonorant be it a vowel or sonorant consonant, thus accounting for why preferred onset clusters are obstruent-plus-sonorant sequences. (However, as Wright 2004 notes, sibilants often will pattern differently from other obstruents since they have strong internal cues for their place of articulation in their frication; this means that obstruent clusters can occur especially if the first member is a sibilant.) On the other hand, a coda consonant favors higher sonority since given their higher intensity (Parker 2002), they have more robust internal perceptual cues. Since a coda will often be followed by either another consonant or word boundary, the robustness of the consonant-internal cues is important for its perception. Thus, while both the second member of an onset and a coda have a preference for a high sonority consonant, the preference holds for somewhat different reasons.

Most formal models of the syllable as well as formal approaches to syllabification have not really sought to incorporate the high sonority preference for both the second member of an onset and the coda consonant. An example of this is the margin hierarchy of Prince \& Smolensky (2004, henceforth P\&S) shown in (2), which serves as a basis for syllabification.

(2) Prince \& Smolensky's (2004) Margin Hierarchy ${ }^{*} \mathrm{M} /[+\mathrm{lo}]>>{ }^{*} \mathrm{M} /[+\mathrm{hi}]>>{ }^{*} \mathrm{M} / \mathrm{r}>>{ }^{*} \mathrm{M} / 1>>{ }^{*} \mathrm{M} / \mathrm{Nasal}>>$ *M/Obstruent

Since the ${ }^{*} \mathrm{M} /$ Obstruent constraint is the lowest ranked among the margin constraints in (2), obstruents are considered to be the most preferred margin consonant. While P\&S's Margin Hierarchy in (2) accounts for the low sonority preference of a single or initial onset consonant, P\&S themselves note (2004: 191-192) the difficulty this hierarchy has in extending to coda consonants and 
16 Formal versus Functional Explanation for a Universal Theory of

conclude that the treatment of the coda is yet to be fully explored in Optimality Theory. Further, it is clear that the Margin Hierarchy in (2) cannot account for the high sonority preference of the second member of an onset cluster.

In addressing this difficulty some researchers have offered proposals to account for the high sonority preference of codas; other researchers, focusing on onset clusters, have made proposals for the preference of onset clusters (or word-initial clusters) to have a sharp sonority rise. As an example of the former, Orgun (2001) addresses the preference for high sonority codas by positing the sonority-based coda markedness hierarchy given in (3).

(3) The Sonority-Based Coda Markedness Hierarchy Argued for by Orgun (2001)

$$
{ }^{*} \text { Coda-t }>>{ }^{*} \text { Coda-n }>>{ }^{*} \text { Coda-r }>>{ }^{*} \text { Coda-w, j }
$$

This coda hierarchy gives preference to higher sonority elements in the syllable coda. An example of an analysis accounting for the sharp sonority rise of onset clusters can be found in Green (2003: 239). He proposes that there is "a universally and intrinsically ranked set of Onset Well-Formedness (OWF) constraints against specific onset clusters in which constraints against onset clusters with falling sonority (e.g., ${ }^{*} \sigma\left[\right.$ SONORANT $^{\wedge}$ OBSTRUENT) ${ }^{1}$ are ranked above those against onset clusters with shallow-rising sonority (e.g., ${ }^{*} \sigma\left[\mathrm{STOP}^{\wedge} \mathrm{NASAL}\right.$ ), which in turn are ranked above those against onset clusters with steep-rising sonority (e.g., ${ }^{*} \sigma$ [STOP^LIQUID)." The ranking of these OWF constraints with respect to other constraints will determine which sequences are possible onsets. Green exemplifies this with Icelandic in which a stop followed by a liquid is a possible (word-internal) onset but not a stop followed by a nasal. Green accounts for this by positing the critical ranking in (4) between the OWF constraints and the

1 The symbol $\wedge$ means "immediately followed by." 
constraint NoCoda.

(4) Icelandic Onset Clusters (word-internal) ${ }^{*} \sigma\left[\mathrm{STOP}^{\wedge} \mathrm{NASAL}>\mathrm{NoCoda}>{ }^{*} \sigma\left[\mathrm{STOP}^{\wedge}\right.\right.$ LIQUID

The consequence of this ranking is that a word-internal stop-nasal sequence will be syllabified as heterosyllabic while the stop-liquid sequence is syllabified as a complex onset. The evalutation tableau are given in (5) and (6). (Vowel lengthening in an initial stressed open syllable is not accounted for.)

(5) $/$ Ekna/ $\rightarrow$ [Ek.na] 'to bait'

\begin{tabular}{|c|c|c|c|}
\hline$/$ Ekna/ & ${ }^{*} \sigma\left[\right.$ STOP^NASAL $^{\wedge}$ & NoCoda & ${ }^{*} \sigma\left[\right.$ STOP^${ }^{\wedge}$ LIQUID \\
\hline a. E:.kna & $* !$ & & \\
\hline b. Ek.na & & $*$ & \\
\hline
\end{tabular}

(6) $/$ soetra/ $\rightarrow$ [soe.tra] 'to slurp'

\begin{tabular}{|c|c|c|c|}
\hline /soetra/ & ${ }^{*} \sigma\left[\mathrm{STOP}^{\wedge} \mathrm{NASAL}\right.$ & NoCoda & ${ }^{*} \sigma\left[\mathrm{STOP}^{\wedge}\right.$ LIQUID \\
\hline a. soe:.tra & & & $*$ \\
\hline b. soet.ra & & $* !$ & \\
\hline
\end{tabular}

While these proposals accounting for the preference of high sonority codas or the sharp rise in sonority for onset clusters are interesting and insightful for the phenomena they consider, they all fundamentally miss the connection that exists between a (single) coda consonant and the second element of an onset, namely, that they are both positions of high sonority (as opposed to the low sonority preference of a single or initial onset consonant). Specifically, Orgun's (2001) coda hierarchy does not extend to a second member of an onset since that is not a coda position. And 
Green's (2003) OWF analysis cannot formally connect the high sonority preference for the second member of a syllable-initial sequence with the high sonority preference of a coda consonant. Thus, while previous proposals have been interesting, they miss the larger connection between coda consonants and onset clusters.

In a series of works, Baertsch (2002), Baertsch \& Davis (2003, 2009), and Davis \& Baertsch $(2005,2011)$ develop a formal universal model of the syllable and syllabification that encodes the high sonority preference for both the coda and second member of the onset. Specifically, they posit the syllable structure in (7) with the margin constraints in (8) and (9). In (7) we see that there are two types of margin consonants: $\mathrm{M}_{1}$ and $\mathrm{M}_{2}$. The $\mathrm{M}_{1}$ positions in the syllable are those that prefer low sonority. This is typically the syllable initial consonant and the second member of a complex coda (the latter position is not further discussed since it is not relevant for our discussion on Winnebago). The $\mathrm{M}_{2}$ consonantal positions are those that prefer higher sonority elements and include a single coda consonant (or first member of a coda cluster) and the second member of an onset cluster. Baertsch and Davis further show that the two $\mathrm{M}_{2}$ positions of the syllable often pattern together. In order to account for the sonority preference of the different syllable positions Baertsch (2002) splits P\&S's Margin Hierarchy in (2) into two hierarchies: an $M_{1}$ hierarchy in (8) that governs the first member of an onset giving priority to low sonority consonants (like P\&S's Margin Hierarchy) and an $\mathrm{M}_{2}$ hierarchy in (9) that governs a single coda as well as the second segment of an onset giving priority to high sonority consonants. (Note here that low vowels and very often high vowels as well are parsed as peaks rather than $\mathrm{M}_{2}$ segments due to low-ranking ${ }^{*}$ Peak/Vowel. We put these in parentheses in (8) and (9) and will not be discussing this aspect.) 
(7) The Split Margin Approach to the Syllable (Baertsch 2002)

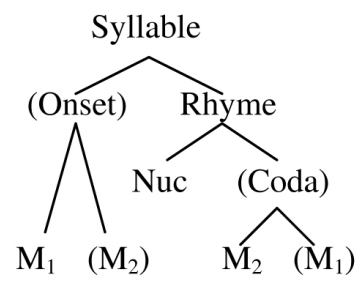

(8) The $M_{1}$ Hierarchy

$\left({ }^{*} \mathrm{M}_{1} /[+\mathrm{lo}]>>{ }^{*} \mathrm{M}_{1} /[+\mathrm{hi}]\right)>>{ }^{*} \mathrm{M}_{1} / \mathrm{r}>>{ }^{*} \mathrm{M}_{1} / 1>>{ }^{*} \mathrm{M}_{1} / \mathrm{Nas}>>$ ${ }^{*} \mathrm{M}_{1} / \mathrm{Obs}$

(9) The $M_{2}$ Hierarchy

${ }^{*} \mathrm{M}_{2} / \mathrm{Obs} \gg>{ }^{*} \mathrm{M}_{2} / \mathrm{Nas}>>{ }^{*} \mathrm{M}_{2} / \mathrm{l} \gg{ }^{*} \mathrm{M}_{2} / \mathrm{r} \gg\left({ }^{*} \mathrm{M}_{2} /[+\mathrm{hi}] \gg\right.$ $\left.{ }^{*} \mathrm{M}_{2} /[+\mathrm{lo}]\right)$

As shown in the various works of Baertsch and Davis this view of syllable structure and syllabification is shown to elucidate a wide variety of phenomena. As an example, we can account for English cross-vowel phonotactic constraints in which forms like [flil], [krar], or [snan] systematically do not occur where the same consonant flanks both sides of a vowel, but only if there is an initial cluster (see Cairns 1988). Possible forms with single consonants flanking both sides of the vowel (e.g., roar or pop) or with a single onset and coda cluster (e.g., nonce, lilt) do occur. Baertsch \& Davis (2003) and Davis \& Baertsch (2011) show that this reflects an OCP-type constraint on the $\mathrm{M}_{2}$ position. Further, Baertsch (2002) demonstrates in detail the application of the split margin model of the syllable to developmental paths in acquisition while Davis \& Baertsch (2005) show the relevance of the split margin syllable for predicting diachronic change in syllable structure. Moreover, Green (2010) reveals the importance of the split margin syllable in accounting for the intriguing pattern of 
syncope in the colloquial Bamana (Bambara) of Bamako Mali where syncope occurs in a way that either results in a sonorant consonant in a coda or as a sonorant consonant as a second member of an onset.

We would contend that the split margin syllable as developed in these works offers a formal explanation for the various phenomena discussed. Consider again the English phonotactic constraint against identical consonants flanking both sides of a vowel mentioned above. The restriction that this only applies if there is an onset cluster is hard to explain from a perceptual or articulatory perspective because it would be odd that $\mathrm{CC}_{\mathrm{i}} \mathrm{VC}_{\mathrm{i}}$ is avoided without also the avoidance of either $\mathrm{C}_{\mathrm{i}} \mathrm{VC}_{\mathrm{i}}$ or $\mathrm{C}_{\mathrm{i}} \mathrm{VC}_{\mathrm{i}} \mathrm{C}$. In all three cases identical consonants flank both sides of the vowel, but it is only the case of $\mathrm{CC}_{\mathrm{i}} \mathrm{VC}_{\mathrm{i}}$ that is systematically prevented. The formal explanation for this is that given the syllable structure in (7) there is an OCP-type constraint on the $\mathrm{M}_{2}$ position within the syllable. It is the margin position that is important. This is clear since in a $\mathrm{C}_{\mathrm{i}} \mathrm{VC}_{\mathrm{i}}$ syllable, the consonant immediately before the vowel would be in $\mathrm{M}_{1}$ position and the one immediately after the vowel would be in $\mathrm{M}_{2}$ position; the constraint does not hold for CVC, rather it holds just in $\mathrm{CC}_{\mathrm{i}} \mathrm{VC}_{\mathrm{i}}$ where the consonants immediately before and immediately after the vowel are both in $\mathrm{M}_{2}$ position. Although our explanation for the ${ }^{*} \mathrm{CC}_{\mathrm{i}} \mathrm{VC}_{\mathrm{i}}$ restriction is formal (i.e., no identical $\mathrm{M}_{2}$ consonants within the same syllable), the syllable structure in (7) is functionally motivated given that there are perceptual reasons for a coda and a second member of an onset cluster to favor a consonant of high sonority. However, from a purely functional view, their patterning together with respect to the phonotactic constraint as well as the other phenomena discussed in the works cited above is not expected, especially given that the coda and the second member of an onset have a high sonority preference for different reasons, as discussed above. Instead, one could see the role of formal phonological constructs such as the split margin syllable in (7) in explaining the pattern of cross vowel 
phonotactics in English.

In the next section we will see the role of the split margin syllable in understanding Dorsey's Law epenthesis in Winnebago.

\section{Dorsey's Law Epenthesis, Sonority, and the Split Margin Syllable}

In this section we consider how sonority and the split margin approach to the syllable play a fundamental role toward explanation of Dorsey's Law in Winnebago. Our contention is that the split margin approach to the syllable offers a deeper explanation as to why Dorsey's Law occurs in Winnebago in comparison to exclusively functionally-oriented explanations. Dorsey's Law in Winnebago inserts an epenthetic vowel to break up a potential obstruent-sonorant sequence, as we see in (10). The inserted vowel has the same quality of the vowel that immediately follows the sonorant consonant. (The Winnebago data are from Miner 1979, 1992, 1993 and Hale \& White Eagle 1980.)

(10) Dorsey's Law Epenthesis in Winnebago
a. /hipres/
[hi.pe.rés]
'know'
b. /krepnã/
[ke.re.p'ã.nã] 'unit of ten'
c. /ha-k-ru-gas/
[ha.ku.rú.gas]
'I tear my own'
d. /š-rugas/
[šu.ru.gás]
'you tear'
e. /sgaa/
[sgaa]
'white'
f. /kšee/
[kšee]
'revenge'
g. /pšoopšoc/
[pšoo.pšóc] 'fine'
h. /haracab-ra/
[ha.ra.cáb.ra] 'the taste'

The data in (10a-c) show typical instances of the application of Dorsey's Law where potential obstruent-plus-sonorant clusters are broken up. The potential cluster could be word-internal or at the 
22 Formal versus Functional Explanation for a Universal Theory of

beginning of the word. As (10b) illustrates, it can occur multiple times within a word. Further, the epenthetic vowel can sometimes carry stress as in (10b). The data in (10c-d) are important because these examples demonstrate that the epenthesis process is part of the synchronic phonology of the language. In (10c) the $/-k /$ is an affix indicating 'one's own' and in (10d) the prefix is a person marker. These affixes can trigger the application of Dorsey's Law. The data in (10e-g) illustrate that obstruent clusters containing a sibilant can surface without any epenthesis. The data item in (10h) shows that Dorsey's law fails to apply over a suffix boundary. This should be contrasted with the nonsuffixal affixes in (10c-d).

The explanation for what motivates Dorsey's Law has engendered some discussion in the literature with different explanations. This is most likely because, as Alderete (1995) has observed, it is somewhat odd for the typologically preferred potential onset cluster (obstruent + sonorant) to be split up by epenthesis in Winnebago while in the same language obstruent-obstruent clusters are allowed to surface. An explanation for why Dorsey's Law epenthesis occurs in Winnebago has to account for several issues: first, why are obstruent-plus-sonorant sequences prevented from surfacing; second, why is the repair strategy epenthesis, and third, why doesn't Dorsey's Law apply over a suffix boundary? We will contend that a full understanding of Dorsey's Law epenthesis requires together both a formal and a functional account. The formal aspect of the explanation under our view makes crucial reference to sonority and the split margin approach to the syllable; it accounts for why potential obstruent-plus-sonorant sequences are targeted for repair. The functional aspect helps to explain why such potential sequences are fixed by epenthesis as opposed to some other mechanism such as deletion. However, before we detail our explanation for Dorsey's Law in Winnebago, we first discuss two separate functional accounts of Dorsey's Law proposed in the literature and the formal account of Alderete (1995).

There are two different functional accounts for Dorsey's Law 
that we will briefly discuss here. First, Blevins (2004) in explaining why a vowel would be inserted between an obstruent and a sonorant suggests that the audible release of the obstruent before the sonorant is misperceived as a vowel. The release is perceived to be colored by the post-sonorant vowel because of anticipatory articulation of vowel gestures. Given that stop consonants in Winnebago have a fairly long release (Bill Anderson, personal communication), this is a plausible explanation, at least to a certain extent. However, at a fundamental level, what the proposal does not explain is why the "misperception" occurs in Winnebago but not in English (or other languages such as Arabic or Berber) where the same underlying sequences are present and where the obstruents are typically released. That is, it fails to answer what is special about Winnebago that makes the "misperception" more likely. We would contend that the answer has to do with the structure of the language.

A somewhat different functional explanation for Dorsey's Law epenthesis is provided by Fleischhacker (2002) and Flemming (2008). They maintain that epenthesis generally is more likely to occur to split up an underlying obstruent-sonorant sequence than to split up an underlying obstruent-obstruent sequence. Under Flemming's account, in particular, this has to do with the close perceptual similarity of obstruent-sonorant sequences with obstruent -V-sonorant sequences. On the other hand, epenthesis is less likely to occur in an obstruent-obstruent sequence because the resulting obstruent-vowel-obstruent sequence would not be that perceptually similar to the underlying obstruent-obstruent sequence. This proposal is framed from the perspective of the P-Map hypothesis along the lines of Steriade (2008) in which alternations occur in a way that is minimally deviant from a target underlying form. However, this perceptual similarity account as applied to Winnebago specifically is somewhat problematic. First, Bill Anderson reports to us that Dorsey's Law vowels in Winnebago have similar duration to underlying vowels, which would not be expected under 
24 Formal versus Functional Explanation for a Universal Theory of

a P-Map account. Second, under this account one would not expect the epenthetic vowel to take on primary stress (as in (10b)) since by stressing the epenthetic vowel the surfacing obstruentvowel-sonorant sequence becomes more distinct from the underlying obstruent-sonorant sequence (see Hale \& White Eagle 1980, Halle \& Vergnaud 1987, Strycharczuk 2009 among others for formal analyses of the interaction of Dorsey's Law with stress). Further, as with the proposal of Blevins (2004), we do not get an explanation as to why in Winnebago, in particular, potential obstruent-plus-sonorant clusters are targeted for repair in a way that is phonologized as opposed to other languages like English, Berber, and Arabic that have the same underlying sequences.

An interesting formal explanation for Dorsey's Law in Winnebago has been offered by Alderete (1995) who raises the question as to why Dorsey's Law would break up potential obstruent-sonorant onset clusters when they are cross-linguistically the most preferred complex onsets. Alderete's (1995: 48) answer is that a syllable contact constraint is active in Winnebago such that there cannot be a sonority rise of greater than one sonority interval over a syllable boundary. Consequently, in Alderete's analysis Dorsey's Law occurs so as to break up bad syllable contact (i.e., rising sonority over a syllable boundary). For example, Alderete assumes that the target syllabification for an underlying form like in (10a) would be [hip.res]. The actual output with epenthesis, [hi.pe.res] avoids the dispreferred syllable contact. The difficulty with this analysis is that it seems to predict that word-initial clusters like the one shown in (10b) should not be broken up because syllable contact is not at issue word-initially. Alderete (1995: 49) suggests that words that seem to begin with such a cluster (such as (10b)) actually contain an initial "silent vowel" so that the syllable contact constraint would apply to them. However, there is no independent evidence for the silent vowel; it neither interacts with stress nor does it have a reflex diachronically (Bill Anderson, personal communication). Further, from a functional perspective, Alderete 
does not offer an explanation for why obstruent-sonorant clusters are repaired by vowel insertion (as opposed to consonant deletion) other than by referencing a constraint ranking in which Dep is the lowest ranked relevant faithfulness constraint. No insight is offered as to why it is ranked low.

We now turn to our proposed explanation for the Dorsey's Law facts in Winnebago. Our analysis will involve both formal and functional considerations in answering the questions posed above: why are obstruent-plus-sonorant sequences in Winnebago prevented from surfacing? Why is the specific repair strategy epenthesis? And why doesn't Dorsey's Law apply over a suffix boundary?

With respect to the first question, what is it about Winnebago that prevents the surfacing of target obstruent-plus-sonorant sequences; functional accounts do not seem to be adequate in addressing this question as pointed out above. The issue can be rephrased as, what is it about the structure of Winnebago that results in a dispreference for the surfacing of obstruent-plussonorant sequences? Alderete's (1995) explanation, though we disagree with it, is a formal one in that it references something about the structure of the language system itself, namely there is a high-ranking syllable contact constraint. On the other hand, a functional explanation may have difficulty in connecting epenthesis to larger structural matters within the language. On our account, which incorporates the split margin approach to the syllable as put forward in (7)-(9) of section 3, there is language-internal pressure for obstruent-sonorant sequences not to surface. The salient observation about Winnebago that is overlooked in the functional accounts of Dorsey's Law is that the language disallows sonorant consonants in coda position (Miner 1993). While this observation may seem unconnected to Dorsey's Law, under the split margin approach to the syllable shown, it is crucially connected. This is because both coda consonants and the second member of an onset cluster are in the $\mathrm{M}_{2}$ position of the syllable. If a language does not allow coda consonants, then as formalized in an optimality- 
theoretic analysis, the entire $\mathrm{M}_{2}$ hierarchy (abbreviated as ${ }^{*} \mathrm{M}_{2}$ in (11)) dominates Dep (the constraint militating against vowel insertion). That is, Winnebago has the constraint ranking ${ }^{*} \mathrm{M}_{2}>>$ Dep. This prevents coda consonants from surfacing. On the other hand, since most elements can appear as a single syllable onset in Winnebago, the $\mathrm{M}_{1}$ hierarchy (abbreviated as ${ }^{*} \mathrm{M}_{1}$ in (11)) is dominated by Dep (i.e., Dep $>>{ }^{*} \mathrm{M}_{1}$ ); this allows a syllable-initial consonant to surface. The tableau in (11) illustrates a Winnebago word with what should be partial reduplication, where, a sonorant can potentially surface in the coda position of the reduplicant, as in candidate (11a). This candidate fails, not because of a syllable contact constraint (which it respects), but because of the high-ranked $\mathrm{M}_{2}$ hierarchy resulting in a dispreference to parse a rhotic in coda position. The winning candidate has an inserted vowel, violating lower ranked Dep. Note in (11) we see a case of epenthesis that is not related to Dorsey's Law.

(11) Winnebago /R+šara/ [šarašara] 'bold in spots'

\begin{tabular}{|c|c|c|c|}
\hline$/$ šar+šara/ & ${ }^{*} \mathrm{M}_{2}$ & Dep & ${ }^{*} \mathrm{M}_{1}$ \\
\hline a. šar.ša.ra & ${ }^{*} \mathrm{M}_{2} /[\mathrm{r}] !$ & & ${ }^{*} \mathrm{M}_{1} / \mathrm{Obs},{ }^{*} \mathrm{M}_{1} / \mathrm{Obs},{ }^{*} \mathrm{M}_{1} /[\mathrm{r}]$ \\
\hline b. ša.ra.ša.ra & & $*$ & ${ }^{*} \mathrm{M}_{1} / \mathrm{Obs},{ }^{*} \mathrm{M}_{1} / \mathrm{Obs},{ }^{*} \mathrm{M}_{1} /[\mathrm{r}],{ }^{*} \mathrm{M}_{1} /[\mathrm{r}]$ \\
\hline
\end{tabular}

Given the high ranked nature of the $\mathrm{M}_{2}$ hierarchy in Winnebago, it follows that complex onsets (which include an $\mathrm{M}_{2}$ position) are disallowed as well. Under the split margin approach to the syllable, a language will not allow onset clusters unless at least a portion of the $\mathrm{M}_{2}$ hierarchy (along with the ${ }^{*}$ ComplexOnset constraint) is dominated by Faith (i.e., Dep in Winnebago). In fact, as shown in (12), even if the ${ }^{*}$ ComplexOnset constraint itself is dominated by Faith, complex onsets will be disallowed unless the relevant $\mathrm{M}_{2}$ constraints are also dominated by Faith. 
(12) Hocank /krepnã/ [ke.re.pã.nã] 'unit of ten'

\begin{tabular}{|c|c|c|c|c|}
\hline$/$ krepnã/ & ${ }^{*} \mathrm{M}_{2}$ & Dep & ${ }^{*} \mathrm{M}_{1}$ & ${ }^{*}$ CompOns \\
\hline a. krep.nã & $* * !$ & & $* *$ & $*$ \\
\hline b. kre.pã.nã & $* !$ & $*$ & $* * *$ & $*$ \\
\hline c. ke.re.pã.nã & & $* *$ & $* * * *$ & \\
\hline
\end{tabular}

Under this analysis the explanation for why obstruent-sonorant sequences do not surface is that the entire ${ }^{*} \mathrm{M}_{2}$ hierarchy is high-ranked. The language does not allow sonorant consonants in the coda position, so there is language-internal pressure not to allow them as a second member of an onset. This is a formal explanation that we couch within the split margin approach to the syllable. ${ }^{2}$

There are two remaining questions. One is how to account for the lack of Dorsey's Law epenthesis over a suffixal boundary as in $(10 \mathrm{~h})$ and the other is to explain why epenthesis occurs as the preferred repair strategy preventing the surfacing of obstruentsonorant sequences. With respect to the first issue we see from (10h), repeated in (13), that Dorsey's Law does not apply over a final stem boundary and the obstruent-sonorant sequence surfaces.

2 An interesting consequence of the split margin approach to the syllable that is discussed in Davis \& Baertsch $(2005,2011)$ is that in general if a language does not allow for coda consonants then it should not have true onset clusters (i.e., an onset that consists of an obstruent followed by a sonorant). This is because, as seen in the tableau in (12), if a language does not have codas then all the ${ }^{*} \mathrm{M}_{2}$ constraints would be ranked higher than the relevant faithfulness constraint (Dep in (12)). Even if, hypothetically, the ${ }^{*}$ CompOns is low ranked (as in (12)), the candidate lacking the complex onset will still win out. While it is a typological question as to whether there are indeed languages that have true onset clusters but lack codas, we believe that such languages are rare. Davis \& Baertsch (2011) suggest that such languages, if they exist, may be covert coda languages. That is, they would allow for codas but they do not have input sequences that result in coda syllabification. Further investigation on this matter is left for future research. 


\section{(13) Lack of Dorsey's Law over a Stem-Final Boundary} /haracab-ra/ [ha.ra.cab.ra] "[ha.ra.ca.pa.ra] 'the taste'

Here we suggest that stem-final codas that are not word final may, in fact, surface as an $\mathrm{M}_{2}$ element compelled by a high ranked alignment constraint requiring a stem-final element to be syllable final, i.e., AlignR (stem, syllable), namely that the right edge of the stem aligns with the right edge of the syllable. The /b/ in (13) is in stem-final position. This alignment constraint prevents Dorsey's Law from applying to (13) as shown in (14).

(14) /haracab-ra/ $\rightarrow$ [haracab-ra] 'the taste'

\begin{tabular}{|c|c|c|c|c|}
\hline /haracab-ra/ & $\begin{array}{c}\text { AlignR } \\
\text { (stem, syllable) }\end{array}$ & ${ }^{*} \mathrm{M}_{2}$ & Dep & ${ }^{*} \mathrm{M}_{1}$ \\
\hline a. ha.ra.cab.ra & & ${ }^{*} \mathrm{M}_{2} / \mathrm{obs}$ & & $* * * *$ \\
\hline b. ha.ra.ca.bra & $* !$ & ${ }^{*} \mathrm{M}_{2} / \mathrm{r}$ & & $* * * *$ \\
\hline c. ha.ra.ca.ba.ra & $* !$ & & $*$ & $* * * * *$ \\
\hline
\end{tabular}

The high ranking nature of the alignment constraint means that a coda can surface only to respect the constraint. We thus understand the lack of application of Dorsey's Law epenthesis to a sequence of a stem-final obstruent plus suffix-initial sonorant as due to an over-riding constraint that requires the right edge of the stem to correspond with the right edge of the syllable. This constraint would be irrelevant to data like in (10c) and (10d) that involve prefixed elements since they would not be at the end of the stem. Thus, Dorsey's Law applies to those sequences but not over a suffixal boundary. ${ }^{3}$

3 As a formal matter that is beyond the scope of the current paper, there is a crucial distinction in the split margin theory to the syllable between a true onset cluster and an adjunct cluster. A true onset cluster consists of an $\mathrm{M}_{1}$ consonant followed by an $\mathrm{M}_{2}$ consonant and typically obeys the sonority sequencing 
With respect to the second issue as to why epenthesis is used as the repair strategy to prevent obstruent-sonorant sequences from surfacing in Winnebago, we could say formally that it is because Dep is the lowest ranking of the relevant faithfulness constraints. However, we believe there is a clear functional explanation for why Dep is ranked low, that is, for why epenthesis occurs as opposed to some other strategy such as deletion of a consonant. As mentioned earlier, Blevins (2004) contends that Dorsey's law epenthesis can be understood as the "misperception" of the audible release of an obstruent as a vowel than before a sonorant consonant. The "misperceived" release is colored by the following vowel because of anticipatory articulation of the vowel gestures. This view is consistent with the observation that Winnebago stop consonants have a rather lengthy release (Bill Anderson, personal communication). Because of the lengthy release, the consonant is less likely to delete. In this sense, part of the explanation for the occurrence of Dorsey's Law in Winnebago is functional along the lines suggested by Blevins (2004). However, the functional explanation does not really answer the deeper question as to why possible obstruent-sonorant sequences are targeted for repair in

principle. We view an adjunct cluster as formally consisting of an $\mathrm{M}_{1}$ consonant followed by another $\mathrm{M}_{1}$ consonant and thus are typically obstruent sequences. In languages that allow them they may occur word-initially or at the beginning of the syllable. As in Winnebago they often contain a sibilant. Further, as in Italian, they often have phonological patterning that is quite distinct from onset clusters (Davis 1990). We would analyze the Winnebago obstruent clusters in (10e-g) as being adjunct clusters, thus not containing an $\mathrm{M}_{2}$ element. While we have not yet fully developed a formal theory of adjunct clusters, we are aware that syllable initial clusters in some languages like Winnebago are always adjunct clusters; in other languages like Spanish they are always true onset clusters, and in still other languages they can be both. For example, in Italian following Davis (1990), word-initial clusters that have a certain sonority distance are true onset clusters while those that do not are adjunct clusters. These two cluster types behave differently phonologically. Just as there are preferred types of true onset clusters, there are also preferences as to what makes for a better adjunct cluster. Regarding the latter, the work of Morelli (1999) is suggestive. 
30 Formal versus Functional Explanation for a Universal Theory of

Winnebago and not in languages like English, Berber, and Arabic where underlying sequences of obstruent-plus-sonorant also occur and where the obstruents are released. As maintained in this paper, there is internal structural pressure from within the phonology of Winnebago for the sonorant not to surface as a second member of an onset since Winnebago does not permit sonorant consonants to surface in the coda. Consequently, this then means that the release of the obstruent consonant before the sonorant in Winnebago is much more susceptible to be misperceived as a vowel than say in a language like English where the internal structural pressure from within the phonology does not exist. Note that the formal explanation cannot really predict that epenthesis would occur as a "repair" as opposed to consonant deletion or some other "repair" for obstruent-plus-sonorant sequences. But the functional analysis cannot really explain why the consonant release before a sonorant in Winnebago is likely to be misperceived as a vowel as opposed to a language like English that has the same underlying obstruentplus-sonorant sequences. It is unable to account for the parallel behavior of a coda and a second member of an onset. In sum, the explanation for Dorsey's Law in Winnebago can only be understood with reference to both the formal and functional factors.

\section{Conclusions}

In this paper we have considered the well-discussed problem of Dorsey's Law in Winnebago and have offered an explanation for the phenomenon by referencing sonority and the split margin approach to the syllable. We have contrasted in this paper functional explanations from formal explanations and have shown that a fuller understanding for the occurrence of Dorsey's Law in Winnebago combines both formal and functional aspects. What we 
want to emphasize is the important role of sonority and syllable structure in accounting for why obstruent + sonorant sequences are not normally allowed to surface in Winnebago. We explain this with respect to the split margin approach to the syllable in which both the coda consonant and the second member of an onset are high sonority elements marked in the same way. Under this view there is internal structural pressure from within the phonology of Winnebago for the sonorant not to surface as a second member of the onset since the language does not permit sonorant consonants to appear in the coda position. These are both $\mathrm{M}_{2}$ positions and display parallel behavior. While as discussed in section 3, the basis for the high sonority preference for these two positions are different, they nonetheless can have a symmetrical patterning as we see in Winnebago. This is neatly captured in the formal analysis by the high-ranked ${ }^{*} \mathrm{M}_{2}$ family of constraints. On the other hand, once sonorant consonants are targeted not to surface in $\mathrm{M}_{2}$ position, functional factors consider the precise nature of the repair. Here given that Winnebago obstruents typically have a long release, perceptual factors come into play in determining that epenthesis is the best strategy preventing sonorants from appearing in $\mathrm{M}_{2}$ position. We conclude by suggesting that deeper explanation in phonology will often involve both formal factors (i.e., the role of language-internal structure) as well as lower-level functional factors that have a basis outside of the language system.

\section{References}

Alderete, J. 1995. Winnebago Accent and Dorsey's Law. University of Massachusetts Occasional Papers 18, 21-51.

Baertsch, K. 2002. An Optimality Theoretic Approach to Syllable Structure: The Split Margin Hierarchy. Ph.D Dissertation. Indiana University. 
32 Formal versus Functional Explanation for a Universal Theory of

Baertsch, K. \& S. Davis. 2003. The Split Margin Approach to Syllable Structure. ZAS Papers in Linguistics 32, 1-14. . 2009. Strength Relations between Consonants: A SyllableBased OT Approach. In K. Nasukawa \& P. Backley (eds.), Phonological Strength 293-324. New York: Mouton de Gruyter. Blevins, J. 2004. Evolutionary Phonology. Cambridge: Cambridge University Press.

Bybee, J. 2001. Phonology and Language Use. Cambridge: Cambridge University Press.

Cairns, C. 1988. Phonotactics, Markedness, and Lexical Representation. Phonology 5, 209-236.

Campbell, L. 1986. American Indian Languages: The Historical Linguistics of Native America. Oxford: Oxford University Press.

Chomsky, N. 1975. Reflections on Language. New York: Random House.

1988. Language and Problems of Knowledge: The Managua Lectures. Cambridge, MA: MIT Press.

Clements, G. 1990. The Role of the Sonority Cycle in Core Syllabification. In J. Kingston \& M. Beckman (eds.), Papers in Laboratory Phonology I: Between the Grammar and Physics of Speech 283-333. New York: Cambridge University Press.

Davis, S. 1990. Italian Onset Structure and the Distribution of "il" and "lo". Linguistics 28, 43-55.

. 2011. Quantity. In J. Goldsmith et al. (eds.), The Handbook of Phonological Theory 103-140. Oxford: Blackwell. Davis, S. \& K. Baertsch. 2005. The Diachronic Link between Onset Clusters and Codas. Berkeley Linguistics Society 31, 397-408.

. 2011. On the Relationship between Codas and Onset

Clusters. In C. Cairns \& E. Raimy (eds.), Handbook of the Syllable 71-97. Leiden: Brill.

Dorsey, J. 1885. On the Comparative Phonology of Four Siouan 
Languages. Annual Report of the Board of Regents of the Smithsonian Institution [for 1883] 919-929. Washington DC: Government Printing Office.

Fleischhacker, H. 2002. Cluster-Dependent Epenthesis Asymmetries. UCLA Working Papers in Linguistics 7, 71-116.

Flemming, E. 2008. Asymmetries between Assimilation and Epenthesis. Paper Presented at the 82nd Annual Meeting of the Linguistic Society of America. Chicago, January 3-6.

Green, C. 2010. Prosodic Phonology in Bamana (Bambara): Syllable Complexity, Metrical Structure, and Tone. Ph.D Dissertation. Indiana University.

Green, T. 2003. Extrasyllabic Consonants and Onset WellFormedness. In C. Fery \& R. van de Vijver (eds.), The Syllable in Optimality Theory 238-253. Cambridge: Cambridge University Press.

Hale, K. \& J. White Eagle. 1980. A Preliminary Metrical Account of Winnebago Accent. International Journal of American Linguistics 46, 117-132.

Halle, M. \& J-R. Vergnaud. 1987. An Essay on Stress. Cambridge, MA: MIT Press.

Hayes, B. 1985. Iambic and Trochaic Rhythm in Stress Rules. Berkeley Linguistics Society 13, 429-446.

Hyde, B. 2011. The Iambic-Trochaic Law. In M. van Oostendorp et al. (eds.), The Blackwell Companion to Phonology 1052-1077. Oxford: Wiley-Blackwell.

Kager, R. 1993. Alternatives to the Iambic-Trochaic Law. Natural Language and Linguistic Theory 11, 381-432.

Miner, K. 1979. Dorsey's Law in Winnebago-Chiwere and Winnebago Accent. International Journal of American Linguistics 45, 25-33.

. 1992. Winnebago Accent: The Rest of the Data. Indiana University Linguistics Club 25th Anniversary Volume 28-53. Bloomington, IN: Indiana University Linguistics Club. . 1993. On Some Theoretical Implications of Winnebago 
34 Formal versus Functional Explanation for a Universal Theory of

Phonology. Kansas Working Papers in Linguistics 18, 111-130. Morelli, F. 1999. The Phontactics and Phonology of Obstruent Clusters in Optimality Theory. Ph.D Dissertation. University of Maryland.

Newmeyer, F. 2003. Grammar Is Grammar and Usage Is Usage. Language 79, 682-707.

Orgun, C. 2001. English R-Insertion in Optimality Theory. Natural Language and Linguistic Theory 19, 737-749.

Parker, S. 2002. Quantifying the Sonority Hierarchy. Ph.D Dissertation. University of Massachusetts.

Prince, A. \& P. Smolensky. 2004. Optimality Theory: Constraint Interaction in Generative Grammar. Malden, MA: Blackwell. Pulleyblank, D. 1988. Underspecification, the Feature Hierarchy, and Tiv Vowels. Phonology 5, 299-326.

Steriade, D. 1982. Greek Prosodies and the Nature of Syllabification.

Ph.D Dissertation. MIT.

1999. Phonetics in Phonology: The Case of Laryngeal

Neutralization. UCLA Working Papers 2, 25-146. . 2008. The Phonology of Perceptibility Effects: The P-map and its Consequences for Constraint Organization. In K. Hanson \& S. Inkelas (eds.), The Nature of the Word: Studies in Honor of Paul Kiparsky 151-179. Cambridge, MA: MIT Press.

Strycharczuk, P. 2009. The Interaction of Dorsey's Law and Stress: A Non-Foot Based Approach. Paper Presented at CUNY Conference on the Foot. City University of New York, January 15-17.

Wright, R. 2004. A Review of Perceptual Cues and Cue Robustness. In B. Hayes et al. (eds.), Phonetically Based Phonology 34-57. Cambridge: Cambridge University Press.

Zec, D. 1995. The Role of Moraic Structure in the Distribution of Segments within Syllables. In J. Durand \& F. Katamba (eds.), Frontiers of Phonology 149-179. London: Longman. 